\title{
DUNALIELLA SALINA IMPROVED OBESITY-ASSOCIATED INFLAMMATION AND OXIDATIVE DAMAGE IN ANIMALS' RODENT
}

\author{
FAROUK K EL-BAZ ${ }^{1 *}$, HANAN F ALY ${ }^{2}$, DALIA B FAYED ${ }^{2}$
}

${ }^{1}$ Department of Plant Biochemistry, National Research Centre, 33 El Bohouthst. (former El Tahrirst.), Dokki, Giza, P.0.12622, Egypt. ${ }^{2}$ Department of Therapeutic Chemistry, National Research Centre, 33 El Bohouthst. (former El Tahrirst.), Dokki, Giza, P.0.12622, Egypt. Email: fa_elbaz@hotmail.com

Received: 05 January 2018, Revised and Accepted: 29 January 2018

ABSTRACT

Objective: The objective of this study is to investigate the efficacy of microalgae Dunaliella salina to improve apelin, oxidative damage, inflammatory, and apoptotic function implicated in high-fat diet (HFD)-induced obesity in rats.

Methods: Fifty male Westar albino rats weighing 150-160 g were fed on HFD for 12 weeks. Treatment of obese rats with D. salina was carried out in a dose $150 \mathrm{mg} / \mathrm{kg}$ body weight as compared to orlistat as anti-obesity standard drug. Blood nuclear factor kappa-B cells (NF-kB), apelin, apoptosis regulator (B-cell lymphoma 2 [BCl2]), monocytes chemoattractan protein-1, paraoxonase-1 (PON1) were determined in serum of different groups. Besides, lipid peroxidation (malondialdehyde [MDA]), glutathione (GSH) levels as well as histopathological examination were investigated in liver tissue of obese rats.

Results: Serum apelin, MDA, and NF-kB levels were significantly high, reached to 97.25, 158.18, 511.433, and 170.73\%, respectively. While significant decrease in PON1 (47.82\%), BCl2 (74.88\%), and GSH (63.54 \%), levels were detected in the obese rats compared to controls. Obvious improvement in all biomarkers under investigation upon treated obese rats with ethanol extract of $D$. salina. Histopathological examination of obese hepatic tissue showed dilatation in the central portal veins associated with inflammatory cells infiltration in the portal area and congestion. However, treatment of obese rats with $D$. salina confirmed biochemical analysis and declared less diffuse inflammatory cells infiltration as well as less focal infiltration in both hepatic parenchyma and portal area with higher improvement in D. salina than drug.

Conclusion: It could be concluded that D. salina has a great ability to improve inflammation associated with obesity as well as damaged hepatic architectures, hence it can be used as a promising anti-obesity nutraceuticals.

Keywords: Apelin, Adiponectin, Obesity, Nuclear factor kappa-B, Monocytes chemoattractant protein-1 - B-cell lymphoma 2, Paraoxonase-1, Dunaliella salina.

(C) 2018 The Authors. Published by Innovare Academic Sciences Pvt Ltd. This is an open access article under the CC BY license (http://creativecommons. org/licenses/by/4. 0/) DOI: http://dx.doi.org/10.22159/ajpcr.2018.v11i5.24622

\section{INTRODUCTION}

Obesity is considered to be major common health problem associated with low grade of inflammatory state [1,2]. Considerable evidence suggested the inflammatory response to dietary fat is mediated by tolllike receptor (TLR) signaling, which result in the activation of nuclear factor kappa-B (NF-kB) and production of inflammatory cytokines, such as interleukin (IL)-1 $\beta$, IL-6, and tumor necrosis factor alpha (TNF- $\alpha$ ) interferon, growth factors, cell adhesion molecules, immune receptors, monocytes chemoattractant protein-1 (MCP-1), and stress proteins [3].

It has been known that oxidative stress in obese subjects is a principle factor to the pathogenesis of obesity-linked with metabolic disorders. Adipocytes secreted apelin which is an adipocytokine. Apelin is well recognized for its anti-obesity and antidiabetic characteristic. Apelin reduced the generation of reactive oxygen species (ROS) in adipocytes, through apelin receptor (APJ) interaction. This is further documented by the knows that apelin elicits enhancement of antioxidant enzymes through pathways of MAPK kinase/extracellular signal-regulated kinase (ERK) and AMPK and decreases prooxidant enzyme production through AMPK pathway [4].

Obesity is connected with oxidative stress [5] which is a principle factor-associated obesity and other metabolic diseases [6]. Adipose tissue regulates homeostasis of metabolism through the release of different metabolic factors and adipocytokines. It was found that fat accumulation in adipocytes increases in parallel with the production of ROS [4]. In addition, ROS overproduction destroys functions of adipocyte. It, for examples, damages glucose uptake by insulin in adipocytes and elicits adipogenesis and lipolysis, resulting in free fatty acids overproduction [4]. Furthermore, overproduction of ROS in adipose tissue causes suppression of antioxidative enzymes, promotes NADPH oxidase expression, and abnormality in the regulation of adipocytokines expression (e.g., adiponectin and IL-6) [4].

It is well recognized that the activity of paraoxonase-1 (PON1) in serum is differ related to PON1 consumption to prevent oxidation [7]. Inhibition activity of PON1 in serum is considered as a risk factor for hypercholesterolemia [8], obesity, and Type 2 diabetes [9]

Apoptosis is considered as one of the most important features of obesity and non-alcoholic fatty liver (NAFLD) [10]. It has been demonstrated that Bax and caspase-3 were induced by cholesterol [11] which may be a principle apoptotic proteins; however, expression of p53 and B-cell lymphoma 2 (BCL2) in steatotic cells did not elevate by cholesterol, speculating critical effect for the mechanisms of cell death in hepatocytes [12].

On the other hand, microalgae are considered as a rich source of carotenoids [13]. In addition, up to $0.2 \%$ of carotenoids were constituted microalgae (Chlorophyceae family), with the highest content of $\beta$-carotene in Dunaliella (up to $1 \%$ dry weight). Hence, they are not only rich purified compounds source but also powerful functional foods that are currently being demonstrated as chemopreventive nutraceuticals against inflammatory and carcinogenic diseases [14]. 
$\beta$-carotene showed antioxidant and anticancer properties which are attributed to its retinol (Vitamin A) [13]. Retinoids have a wide range of biological activities and can improve several processes such as reproduction, embryogenesis, growth, differentiation, proliferation, apoptosis, vision, bone formation, metabolism, hematopoiesis, and immunological processes [13].

B-carotene as an anti-inflammatory activity has been demonstrated in many models in vitro and in vivo [15]. Although $\beta$-carotene could act preventively on intestinal inflammatory diseases. The efficacy was attributed to different molecular target attenuation, such as NF-kB, COX-2, and matrix metalloproteinase 9 (MMP-9). Dunaliella bardawil was used against bowel inflammation induced by acetic acid [13]. $\beta$-carotene rich in D. salina exhibited the growth inhibition activity and proapoptotic effects on human colon cancer cell lines, many types of cancer, and degenerative diseases in vitro and in vivo [13] probably due to their antioxidant and anti-inflammatory activities [16].

Hence, the present study is designed to evaluate the role of D. salina in improving oxidative damage, inflammatory, and antiapoptotic biomarkers associated with high-fat diet (HFD)-induced obesity in rats.

\section{METHODS}

\section{Cultivation of $D$. salina}

The organism was grown in conical flask $5 \mathrm{~L}$ containing BG11 nutrient media according to Stanier et al. as shown in Table 1 [17].

One ml of the micronutrient solution was added to the culture medium. After autoclaving and cooling, $\mathrm{pH}$ of medium is about 7. The culture was harvested by centrifugation, dried at $40^{\circ} \mathrm{C}$, and then grounded into homogeneous fine powder.

\section{Ethanolic extract preparation of $D$. salina}

For the preparation of the ethanolic extract, $100 \mathrm{~g}$ of $D$. salina powder was soaked in ethanol (80\%) and shacked on shaker (Heidolph UNIMAX 2010) for $48 \mathrm{~h}$ at $150 \mathrm{rpm}$. The extract was filtered using a Buchner funnel and Whatman No. 4 filter paper, and the algal residue was reextracted with the addition of fresh $80 \%$ ethanol for another 2 times. Combined filtrates were concentrated using rotary evaporator (Heidolph, Germany) at $40^{\circ} \mathrm{C}$ under vacuum. The resulting dry extract was evaporated on a rotary vacuum evaporator to dryness. The dry extract was stored at $-20^{\circ} \mathrm{C}$ in a freeze and kept for further analysis [18].

\section{Biological assay}

\section{Experimental animals}

Male albino rats $(n=50)$ weighted $150 \pm 20$ g were obtained from the Animal House of the National Research Center (NRC). Animals were quarantined and allowed to acclimate for 10 days before beginning experimentation. They were housed 10/cage under temperature-

Table 1: BG11 nutrient composition

\begin{tabular}{|c|c|}
\hline Macronutrient & g/L \\
\hline $\mathrm{NaNO}_{3}$ & 1.5 \\
\hline К2HPO4\# & 0.04 \\
\hline MgSO4.7H2O & 0.075 \\
\hline $\mathrm{CaCl} 2.2 \mathrm{H} 2 \mathrm{O}$ & 0.036 \\
\hline Citric acid & 0.006 \\
\hline Ferric ammonium citrate & 0.006 \\
\hline EDTA (disodium magnesium salt) & 0.001 \\
\hline $\mathrm{Na} 2 \mathrm{CO} 3$ & 0.02 \\
\hline Micronutrient & $\mathrm{g} / \mathrm{L}$ \\
\hline Н3В03 & 2.86 \\
\hline $\mathrm{MnCl} 2.4 \mathrm{H} 2 \mathrm{O}$ & 1.81 \\
\hline ZnSO4.7H2O & 0.222 \\
\hline $\mathrm{Na} 2 \mathrm{MoO} 4.2 \mathrm{H} 2 \mathrm{O}$ & 0.39 \\
\hline $\mathrm{CuSO} 4.5 \mathrm{H} 2 \mathrm{O}$ & 0.079 \\
\hline Co (NO3) $2.6 \mathrm{H} 2 \mathrm{O}$ & 0.0494 \\
\hline
\end{tabular}

controlled environment $\left(26-29^{\circ} \mathrm{C}\right)$ with a fixed light/dark cycle with free access to water and food. All procedures of the present study were performed according to the Ethical Committee of the NRC, Egypt, provided that the animals will not suffer at any stage of the experiment.

\section{Induction of obesity in rats}

Obesity was induced in rats according to the method of Adaramoye et al. [19] by feeding rats' HFD (lard), cholesterol was orally administrated at a dose of $30 \mathrm{mg} / 0.3 \mathrm{ml}$ olive oil/1 $\mathrm{kg}$ animal 5 times a week for 12 consecutive weeks, lard fat was mixed with normal diet (ND) (1 kg of animal lard was added to $5 \mathrm{~kg}$ of ND), and the occurrence of obesity was determined by measuring body weight gain percentages and visceral and fecal fat percentages.

\section{Doses and routes of administration}

Obese rats received an oral dose of $2 \mathrm{mg} / \mathrm{kg}$ body weight dissolved in distilled water of the anti-obesity reference drug, orlistat (12 mg $\backslash$ Kg body weight) for 6 weeks [20]. Obese rats treated with orally administered $150 \mathrm{mg} / \mathrm{Kg}$ body weight of $D$. salina ethanolic extract for 6 weeks [21].

\section{Assay of paraoxonase activity}

The rate of paraoxon hydrolysis was monitored the increase of absorbance at $405 \mathrm{~nm}$ and $25^{\circ} \mathrm{C}$. The basal assay mixture included $1.0 \mathrm{mM}$ paraoxon and $1.0 \mathrm{mM} \mathrm{CaCl} 2$ in $0.05 \mathrm{M}$ glycine buffer, $\mathrm{pH}$ 10.5. 1 unit (IU) of PON activity is defined as $1 \mu \mathrm{mol}$ of p-nitrophenol formed per min, and activity was expressed as $U / 1$ of serum [22].

\section{Determination of MCP-1 protein}

MCP-1 protein levels in serum were measured using a solid-phase sandwich enzyme-linked immunosorbent assay (MCP-1 Quantikine enzyme-linked immunosorbent [ELISA] kit, R\&D systems, Abingdon, UK). Briefly, $100 \mu \mathrm{l}$ of duplicated samples or standards (recombinant human MCP-1) were incubated ( $2 \mathrm{~h}$ at room temperature) in the wells precoated with the primary antihuman MCP-1 antibody. After incubation, wells were washed 3 times and horseradish peroxidaseconjugated polyclonal antibodies against MCP-1 were added (for $2 \mathrm{~h}$ at room temperature). Finally, tetramethylbenzidine substrate solution was applied for $30 \mathrm{~min}$, and after stopping the reactions by $2 \mathrm{M}$ sulfuric acid, the absorbance was measured at $450 \mathrm{~nm}$ (with correction at $540 \mathrm{~nm}$ ). The data were evaluated with KIM-E software (USOL, Prague, Czech Republic); the detection limit of the MCP-1 assay was $5.0 \mathrm{Pg} / \mathrm{ml}$.

\section{Quantification of NF-kB}

NF-kB was measured in serum using commercially available human NF-kB ELISA kit (Glory Science Co., Ltd., Del Rio, TX, USA) according to manufacturer instructions. The kit uses a double antibody sandwich ELISA assay to assay the level of NF-kB. The detection range of the kit is 100-2000 U/l.

\section{Determination of lipid peroxide}

Lipid peroxidation was assayed in liver tissue homogenate by measuring the thiobarbituric acid-reacting substances as previously described by Ruiz-Larrea et al. [23] and Prijant et al. [24] in which the thiobarbituric acid reactive substances react with thiobarbituric acid to produce a red-colored complex having peak absorbance at $532 \mathrm{~nm}$ (using ultraviolet-VI8 recording spectrophotometer, Shimadzu Corporation, Australia).

\section{Determination of BCL2}

The level of serum BCL2 was determined by double-antibody sandwich enzyme-linked immunosorbent assay kit according to the manufacturer's instructions (Biosystems, Egypt,).

\section{Apelin-12}

Serum apelin-12 levels were determined by ELISA (apelin-12 ELISA kit, Phoenix Pharmaceuticals, Belmont, CA, USA) (sensitivity: [Minimum detectable concentration] $=0.15-0.25 \mathrm{ng} / \mathrm{ml}$, intra-CV: $5 \%$, and interCV: $14 \%$ ) 
Marker for antioxidant

Glutathione (GSH) was demonstrated using 5, 5' -dithiobis 2-nitrobenzoic acid acid in phosphate buffer and the formed color was measured at $412 \mathrm{~nm}$ as described by El-Baz et al. [25]

\section{Experimental design}

Fifty male Wistar albino rats (5-6 weeks-old) weighing at $155.00 \pm 5.00 \mathrm{~g}$ (mean \pm standard deviation [SD]) (weight of rats on the day received from supplier) after adaptation period to the environment., the rats were randomly divided into five groups ( $\mathrm{n}=10 /$ group) as follows:

- Group (1): Control rats received normal diet (ND)

- Group (2): Control rats administered ND and treated with $150 \mathrm{mg} / \mathrm{g}$ body weight of ethanolic extract of $D$. salina

- Group(3): HFD treated rats for 12 weeks

- Group (4): Obese rats treated for 6 weeks with $150 \mathrm{mg} / \mathrm{kg}$ body weight of ethanolic extract of D. salina (HFD/DS)

- Group (5): Obese rats treated for 6 weeks with anti-obesity standard drug orlistat (12 mg/kg body weight) (HFD/odd ratio). Health conditions of all rats were monitored daily and no adverse events were observed throughout the study. At the beginning of the experiments, the weights of all rats were recorded at $155.00 \pm 5.00 \mathrm{~g}$ (mean $\pm \mathrm{SD}$ ) (weight of rats after 10 days of acclimatization). All experiments and biochemical analysis were conducted using 50 rats with triplicate measurements. The permission to conduct this study was according to the ethics of NRC, Egypt.

\section{Blood sample}

Blood samples were obtained following an overnight fasting state at the end of treatment (week 12) at 8 a.m. Samples were withdrawn from a cubital vein into blood tubes under diethyl ether anesthesia and immediately stored on ice at $4^{\circ} \mathrm{C}$. The serum was then separated from the cells by centrifugation at $3000 \mathrm{rpm}$ for $10 \mathrm{~min}$, and they were stored until analyzing at $-80^{\circ} \mathrm{C}$ [26]. After 12 and 18 weeks of treatment, all the rats were sacrificed and the liver was removed for biochemical analysis of antioxidant. Part of the liver was fixed in formalin (10\%), for histopathological examination.

\section{Homogenization of hepatic tissue}

Homogenization of hepatic tissue was carried out using saline solution $(1: 10 \mathrm{w} / \mathrm{v})$ for the determination of lipid peroxide (malondialdehyde [MDA]) and GSH.

\section{Histological investigation}

Liver tissue slices were fixed in $10 \%$ buffer formalin. After fixation, paraffin $4 \mathrm{pm}$ hick sections were taken and stained by hematoxylin and eosin $(H \& E \times 200)$ and examined microscopically [27].

\section{Statistical analysis}

We compared the data between the different groups using the SPSS computer program version 8 coupled with a costate computer program, where unshared letters are statistically significant at $p \leq 0.05$.

\section{RESULTS}

The present results demonstrated an insignificant change in control rats treated with $D$. salina as compared to control, while obese rats showed significant increase in NF-kB and MCP-1 levels upon treated obese rats with ethanolic extract of $D$. salina with percentages 511.433 and $170.73 \%$, respectively, as compared to control. Whereas, a significant decrease in $\mathrm{BCl} 2$ reached to $74.88 \%$. Marked amelioration in NF-kB, BCl2, and MCP-1 levels in obese rats treated with $D$. salina with percentages of amelioration $378.44,36.16$, and $112.19 \%$, respectively, compared to reference drug (318.47, 38.65 and 63.41 respectively). (Table 2).

In addition, there was an insignificant change in apelin, PON, MDA, and GSH levels in control rats treated with D. salina as compared to untreated control one. However, obese rats demonstrated significant increase in apelin and MDA levels with percentages 97.25 and 158.18\%, respectively, while there was a significant reduction in PON1 activity and GSH level with percentages 47.82 and $63.54 \%$, respectively, as compared to control. Medication of obese rats with D. salina demonstrated marked improvement in apelin, PON1, MDA, and GSH levels with percentages $67.50,52.17,127.27$, and $41.14 \%$, respectively, compared to standard drug $(58.78,29.57,114.55$, and 16.83\%, respectively) (Table 3).

\section{Histopathological examination}

Histopathological examination of control rats showed no histopathological alteration and normal histological structure of the central vein and surrounding hepatocytes in the parenchyma (Fig. 1). Furthermore, control rats treated with D. salina showed no histopathological alteration (Fig. 2). However, photomicrograph of obese rats fed HFD showed dilatation in the central portal veins associated with inflammatory cells infiltration in the portal area and congestion (Figs. 3a and 3b). Photomicrograph of obese rats treated with $D$. salina and orlistat standard drug showed less diffuse inflammatory cell infiltration as well as less focal infiltration in both hepatic parenchyma and portal area with higher improvement in D. salina than drug (Figs.4a and $4 \mathrm{~b}$ ).

\section{DISCUSSION}

It was suggested that the enhanced hypothalamic TLR4/NF-kB and the release of inflammatory cytokines were incorporated in the imperfect food intake after dietary fat exposure [28]. In the present study, we found that NF-kB NF-kB was significantly higher in obese rats induced by HFD compared with normal control rats. Similar results were found

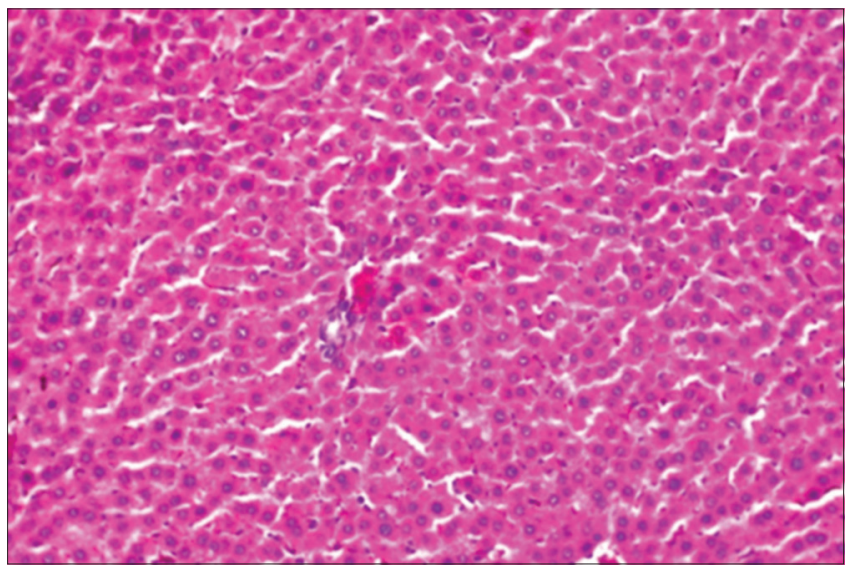

Fig. 1: Photomicrograph of control rats showed no histopathological alteration and the normal histological structure of the central vein and surrounding hepatocytes in the parenchyma $(\mathrm{H}$ and $\mathrm{E} \times 200)$

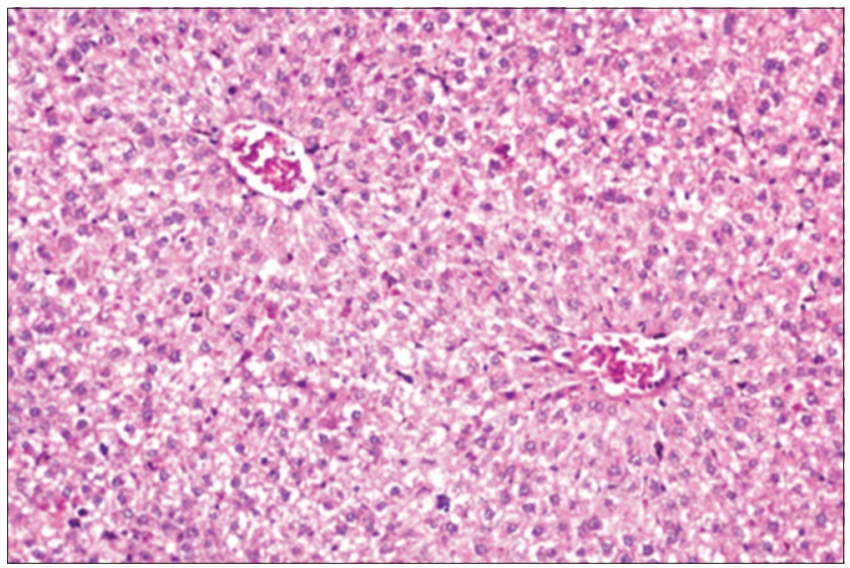

Fig. 2: Photomicrograph of control rats treated with Dunaliella salina and showed that there was no histopathological alterations ( $\mathrm{H}$ and $\mathrm{E} \times \mathbf{2 0 0})$ 
Table 2: Effect of $D$. salina on inflammatory and apoptotic markers in obese rats

\begin{tabular}{|c|c|c|c|c|c|}
\hline \multirow[t]{2}{*}{ Biomarkers } & \multicolumn{5}{|c|}{ Groups } \\
\hline & Control/ND & Control/ND/DS & HFD & HFD/DS & HFD/OR \\
\hline NF-kB (U/l) & a $52.50 \pm 5.00$ & ${ }^{\mathrm{a}} 48.00 \pm 8.01$ & b321.00 \pm 21.9051 & ${ }^{c} 122.32 \pm 2.90$ & ${ }^{\mathrm{d}} 153.80 \pm 4.78$ \\
\hline$\%$ change & & -8.57 & 1.43 & 132.99 & 192.95 \\
\hline$\%$ improvement & & & & 378.44 & 318.47 \\
\hline $\mathrm{BCl} 2(\mu \mathrm{g} / \mathrm{l})$ & ${ }^{\mathrm{f}} 13.22 \pm 0.16$ & ${ }^{f} 13.00 \pm 2.00$ & e $3.32 \pm 0.21$ & a $8.10 \pm 0.34$ & a $8.43 \pm 1.14$ \\
\hline$\%$ change & & 1.66 & 74.88 & 38.73 & 36.23 \\
\hline$\%$ improvement & & & & 36.16 & 38.65 \\
\hline MCP-1 (Pg/ml) & a $8.20 \pm 0.54$ & a $8.00 \pm 2.00$ & " $22.20 \pm 2.00$ & ${ }^{c} 13.00 \pm 0.99$ & $\mathrm{~d} 17.00 \pm 0.79$ \\
\hline$\%$ change & & 2.40 & 170.73 & 58.54 & 107.31 \\
\hline$\%$ improvement & & & & 112.19 & 63.41 \\
\hline
\end{tabular}

ND: Normal diet, ND/DS: Rats feed ND and treated orally with D. salina extract for 4 weeks. HFD/DS: Rats feed with HFD for 12 weeks and treated orally with D. salina for 4 weeks post-induction. FHD/OR: Rats feed HFD and treated orally for 4 weeks with standard drug orlistat. Statistical analysis is carried out using the SPSS computer program, combined with a costate computer program, where unshared letter is statistically significant at $\mathrm{P} \leq 0.05$. NF-kB: Nuclear factor kappa-B, MCP-1: Monocytes chemoattractant protein-1, BCl2: B-cell lymphoma 2, HFD: High-fat diet, D. salina: Dunaliella salina, OR: Orlistat

Table 3: Effect of $D$. salina on apelin, antioxidant, oxidative, and apoptotic biomarkersin obese rats

\begin{tabular}{|c|c|c|c|c|c|}
\hline \multirow[t]{2}{*}{ Biomarkers } & \multicolumn{5}{|c|}{ Groups } \\
\hline & Control/ND & Control/ND/DS & HFD & HFD/DS & HFD/OR \\
\hline Apelin(ng/l) & ${ }^{\mathrm{k}} 400.00 \pm 23.90$ & k378.00 20.90 & $189.00 \pm 21.89$ & $\mathrm{~h} 19.00 \pm 9.80$ & $\mathrm{~d} 553.86 \pm 11.00$ \\
\hline$\%$ change & & 5.50 & 97.25 & 29.75 & 38.47 \\
\hline$\%$ improvement & & & & 67.5 & 58.78 \\
\hline PON-1 (kU/l) & ${ }^{\mathrm{i}} 230.00 \pm 11.90$ & ${ }^{\mathrm{i}} 227.00 \pm 10.00$ & ${ }^{\mathrm{f}} 120.00 \pm 4.88$ & $200.00 \pm 3.80$ & $\mathrm{a} 188.00 \pm 11.10$ \\
\hline$\%$ change & & 1.30 & 47.82 & 34.78 & 18.26 \\
\hline$\%$ improvement & & & & 52.17 & 29.57 \\
\hline MDA (umol/mg protein) & ${ }^{\mathrm{a}} 0.55 \pm 0.16$ & a $0.45 \pm 0.06$ & ${ }^{\mathrm{h}} 1.42 \pm 0.20$ & $\mathrm{~g}_{0} .72 \pm 0.08$ & ${ }^{\mathrm{g}} 0.79 \pm 0.09$ \\
\hline$\%$ change & & 18.18 & 158.18 & 30.90 & 43.64 \\
\hline$\%$ improvement & & & & 127.27 & 114.55 \\
\hline GSH (ug/mg protein) & ${ }^{\mathrm{a}} 48.79 \pm 5.21$ & a $55.70 \pm 5.21$ & b $17.79 \pm 1.20$ & $37.88 \pm 0.90$ & $\mathrm{~d} 26.00 \pm 0.32$ \\
\hline$\%$ change & & 14.16 & 63.54 & 22.36 & 46.71 \\
\hline$\%$ improvement & & & & 41.18 & 16.83 \\
\hline
\end{tabular}

ND: Normal diet, ND/DS: Rats feed ND and treated orally with D. salina extract for 4 weeks. HFD/DS: Rats feed with HFD for 12 weeks and treated orally with $D$. salina for 4 weeks post-induction. FHD/OR: Rats feed HFD and treated orally for 4 weeks with standard drug orlistat. Statistical analysis is carried out using the SPSS computer program, combined with a costate computer program, where unshared letter is statistically significant at P $\leq 0.05$. PON-1: Paraoxonase-1, MDA: Malondialdehyde, GSH: Glutathione, HFD: High-fat diet, D. salina: Dunaliella salina, OR: Orlistat

by Zhang et al. [29]. It was found that inflammation of hypothalamus post-chronic consumption of HFD could not only make changes in feeding and body weight but also influence body weight-independent state to initiate systemic glucose intolerance, and the mechanism illustrated central leptin and insulin resistance induction [3].

Further, NF-kB is activated by oxidative stress, bacterial endotoxin, and cytokines. It induces liver damage related to different agents and pathogens [30], besides enhancement of NF-kB is consider a principle marker in the acute liver failure [30]. NF-kB and TNF- $\alpha$ roles are act as inflammatory response mediators in steatohepatitis nutritional model [31]. In obese condition, the pathways of pro-inflammatory response could initiate from stressed hepatocytes through NF-kB activation. Alternatively, NF-kB -activated Kupffer cells produced TNF- $\alpha$, IL-1 $1 \beta$, and other cytokines which could enhance NF-kB in neighboring hepatocytes [31].

In obese condition, excess fat lipotoxic effects may stimulate TNF- $\alpha$ production. Once produced, NF-kB/TNF- $\alpha$ cycle becomes selfmaintaining [32]. It likely that TNF- $\alpha$ chronic exposure induces inflammatory cells accumulation in the liver, promoting hepatocytes damaging factors produced from activated monocytes [32]. This is indicated in the current results in the histopathological examination which revealed dilatation in the central portal veins associated with inflammatory cells infiltration in the portal area and congestion (Figs. 3a and 3b).

The present results revealed a significant decrease in BCL2 in obese rats which is run in parallel with the study of Briscini et al. [33], who demonstrated that obese rats' adipocytes recorded low ratios of BCL2/ Bax mRNA and protein. BCL2 is proapoptotic and antiapoptotic factors. BCL2 and related proteins function are concerned with their efficacy to prevent apoptosis pathways of mitochondrial. Apoptotic process implies damage of outer membrane of mitochondria and the release of cytochrome $\mathrm{C}$ intermembrane and other proteins into the cytosol, which in turn stimulates death-driving caspase proteolytic enzymes that organize the disassembling of the cell, and this process is regulated by BCL2. Hence, by stopping proapoptotic protein Bax redistribution to the mitochondria, BCL2 prevents mitochondria cytochrome $\mathrm{C}$ from release and subsequent caspase proteins activation [34]. Further, the present investigation declared that HFD significantly increased serum MCP-1. These results are in concomitant with Chen et al. [35] who declared that the expression of MCP-1 and MCP-3 in rats was induced by HFD. The high expression level of MCP-1 in adipose tissue leads to the increase in plasma MCP-1 levels post 4 weeks HFD feeding. Monocytes slowly infiltrated and accumulated in the adipose tissue with an increase in the size of adipocytes, which subsequent stimulated expression of MCP1. It was found that in response to increase in oxidized lipids, adipose MCP- 1 and MCP- 3 were induced. Furthermore, MCP- 1 expression was stimulated by TNF- $\alpha$ in cultured adipocytes, and hence, may act to strengthen the expression of adipocyte MCP-1 [36]. Besides, hepatic MCP-1 has a principle effect in hepatic disorders through stimulation of Kupffer cells by HFD to release markedly high MCP-1 amounts [30].

Indeed, the specific overexpression of mice adipose tissue MCP-1, in turn, leads to insulin resistance development, inflammation, and hepatic 
steatosis and fibrosis by eliciting hepatic stellate cells migration [37] (as indicated in the histological investigation, (Figs. 3a and 3b)).

Considering apelin which is a novel adipokine, the present results showed a significant increase in its level in obese rats induced by HFD. The apelinergic system has been demonstrated to be implicated in the high prevalence disorders such as obesity, glucose intolerance, and diabetes mellitus Type II [38]. Plasma levels of apelin are markedly elevated independently of diet composition in obese mice and humans with hyperinsulinemia [32]. It was found that apelin connected with APJ, which subsequent leads to protein kinase B (Akt) phosphorylation and ERK in different cell. Further, the system of APJ/apelin enhances the expression of adhesion molecule-1 (ICAM-1) through NF-kB/c-Jun N-terminal kinase (JNK) signal pathway [39]. In addition, Yasuzaki et al. [40] declared that apelin/APJ signaling may stimulate Fas-induced hepatic damage in mice injected with anti-Fas antibody (Jo2) through JNK phosphorylation.

On the other hand, treatment of obese rats with $D$. salina extract improved the inflammatory and antiapoptotic markers, MCP-1, and apelin levels. This biochemical observation is documented in histopathological examination of obese rats liver treated with $D$. salina (Figs. 4a and 4b), which may be attributed to D. salina-enriched carotenoids exhibited and anti-inflammatory activities [41]. In addition, $D$. salina treatment inferred a notable downregulation of NF$\mathrm{kB}, \mathrm{MCP}-1$, apelin, and MDA levels, while the extract upregulated BCL2, $\mathrm{GSH}$, and PON1levels. It could be due to the potential anti-inflammatory activity of carotenoids, especially carotenes [41]. Chiu et al. [41] added that the COX-2 protein expression was substantially downregulated by treatment with a carotenoid extract of $D$. salina in lipopolysaccharideinduced RAW 267.4 cell model. Likewise, Bai et al. [42] and Jang et al. [43] pointed out that $\beta$-carotene can inhibit the translocation of NF-p65 subunit from cytosol to the nucleus and thereby halt the inflammatory cascade. Hence, we speculate that $D$. extract rich in $\beta$-carotene can block the translocation of transcription factor (NF-p65/p50 subunit) and thus downregulate COX-2 protein expression and thereby exert antiinflammatory activity as approved by the modulatory effect of $D$. salina on inflammatory reaction, resulting from obesity induced by HFD (Figs. $4 \mathrm{a}$ and $4 \mathrm{~b})$.

Jayappriyan et al. [44] and Palozza et al. [45] also indicated that $\beta$-carotene can interfere with cell growth (antiproliferative) by halting the cell cycle division through inhibiting cyclin A as well as induce apoptosis by downregulating antiapoptotic proteins such as BCL2 in human colon adenocarcinoma cell line. However, D. salina extract rich in carotenoids would not induce cell death in normal cells, rather only in cancer cells, and thus demonstrate its anticarcinogenic activity. In the present study, D. salina extract acts as an antiapoptotic agent, upregulated BCL2 anti-apoptotic marker. This statement clearly indicated that D. salina extract acted as an antiobesity-associated with anti- inflammatory agents not only by triggering anti-apoptosis rather it effectively reduced inflammatory cells reaction. Qiu et al. [46] proved that lycopene could regulate the expression of different protein involved in apoptosis, antiproliferation, antioxidant, andanti-inflammation, and thereby attenuate the progression of prostate cancer.

The current results showed inhibition of PON1 activity in serum of obese rats. The mechanism involved increased generation of ROS in the liver of obese rats as presented by the detected high levels of MDA. It was found that the inhibition activity of liver microsomal PON1 is considered as the starting point of biochemical alteration contributed to lipid peroxidation and hepatic damage noticed in rats injected with $\mathrm{CCl}_{4}$-induced cirrhosis [47].

In another explanation, PON1 mRNA expression is downregulated by the pro-inflammatory cytokines as IL-1 and TNF- $\alpha$ in HepG2 cells. This cytokine promoted a decrease in the production of PON1 by the liver [48]. Hence, PON1 inhibition activity in sera of patients with chronic hepatic damage was suggested to be attributed to the degree of hepatic injury [22].
Obesity-induced pathology is thought to be occurred as a result of high level of lipid peroxidation. The data presented in the current study clarify that obesity elevated MDA level in hepatic tissue. This is in agreement with the results of Vincent et al. [49] and Amirkhizi et al. [50], who showed that obesity can produce a high level of lipid peroxidation by developing and growing cell damage as a consequence of the large body mass pressure. Cell damage stimulates cytokines production, particularly TNF-a, which initiates ROS from the tissues which lead to lipid peroxidation production [51]. Furthermore, the hypertriglyceridemia observed in obese rats may related to the change in the balance of oxidant-antioxidant status, suggesting that an elevation in the free fatty acids bioavailability can enhance lipid peroxidation [50]. It has been found that the body of animals had a powerful mechanism to stop tissue damage by free radical; this is achieved by a collection of proteins and endogenous antioxidant enzymes as glutathione S-transferase, superoxide dismutase, catalase, glutathione peroxidase, glutathione reductase, and GSH. Hence, when the production of ROS exceeds the defense of antioxidant, oxidative stress produce leading to different pathological conditions [51]. The decrease in the enzymes of antioxidant may be related to the fast consumption and exhaustion of enzyme storage in combating free radicals produced during obesity progress. The inhibition in PON-1 activity and reduced GSH level could be occurred as a result of changed synthesis and/or HDL secretion, secondary to destroyed activity of lecithin-cholesterol acyltransferase. PON-1 may be inhibited under oxidative stress, by S-glutathionylation, a redox-controlled mechanism, described by the combination between a protein thiol and oxidized GSH forming mixed disulfide [51].

The ameliorative effects of $D$. salina on MDA, GSH levels as well as PON1 activity may be due to the presence of several carotenoids such as all-trans-lutein, all-trans-zeaxanthin, all-trans- $\alpha$-carotene, all-trans$\beta$-carotene, and 9-cis- $\beta$-carotene. Nevertheless, all-trans- $\beta$-carotene and 9 -cis- $\beta$-carotene are the major carotenoids present in D. salina

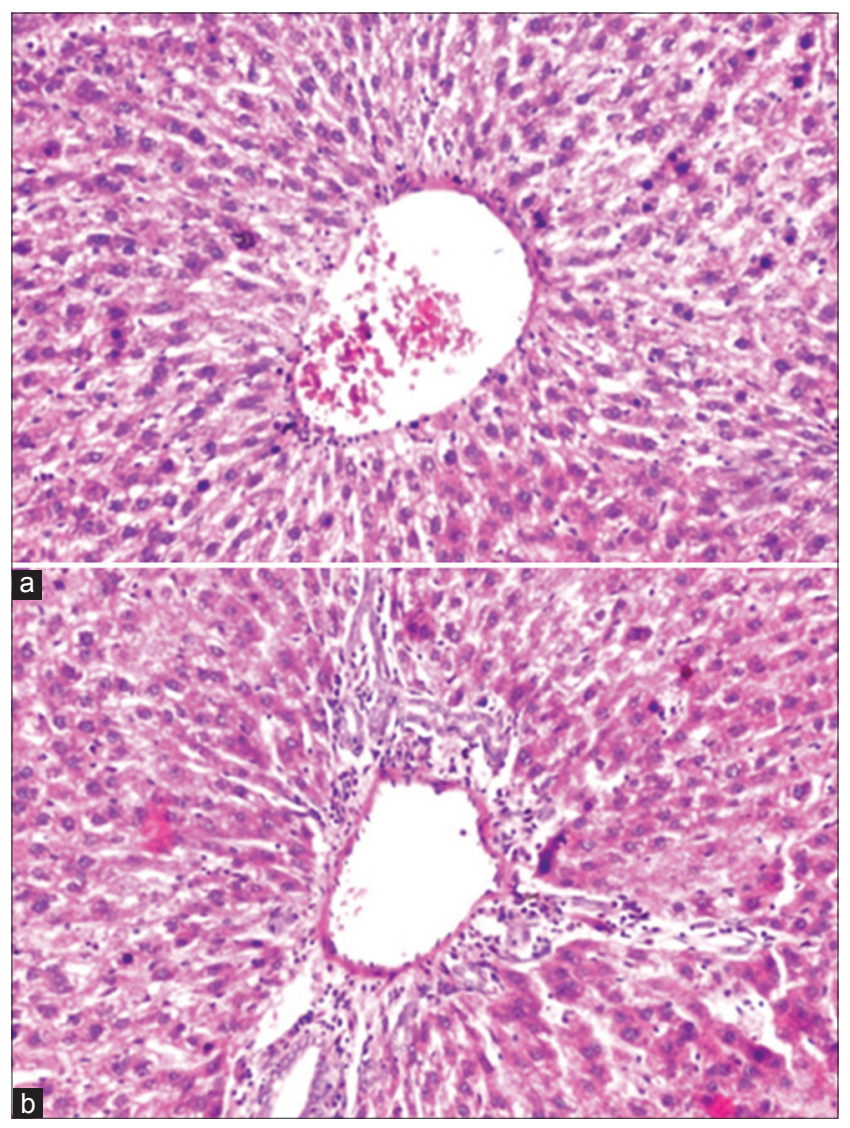

Fig. 3: (a and b) Photomicrograph of obese rats fed high-fat diet and showed dilatation in the central and portal veins associated with inflammatory cells infiltration in the portal area $(\mathrm{H}$ and $\mathrm{E} \times 200)$ 


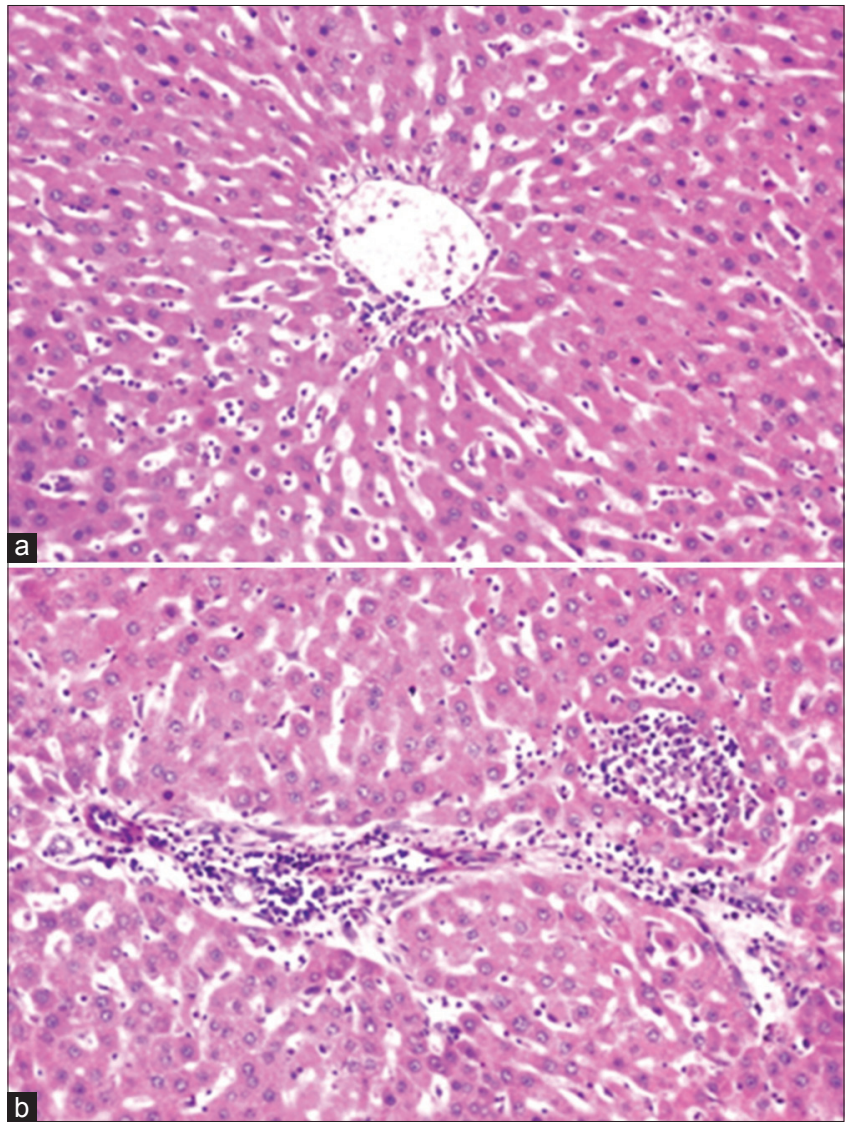

Fig. 4: (a and b) Photomicrograph of obese rats treated with (a) Dunaliella salina and orlistat standard drug (b) showed less diffuse inflammatory cells infiltration as well as less focal infiltration in both hepatic parenchyma and portal area with higher improvement in D. salina than drug ( $\mathrm{H}$ and $\mathrm{E} \times \mathbf{2 0 0})$

extract. Similarly, García-González et al. [52] and Yang et al. [53] also reported that all-trans- $\beta$-carotene and 9-cis- $\beta$-carotene were present in higher concentration than other carotenoids. Moreover, Ben-Amotz and Fishier [54] indicated that Dunaliella species (D. bardawil) contained about $50 \%$ of 9 -cis- $\beta$-carotene of total carotenoid contents. The antioxidant analysis showed that the extract enriched with carotenoids would effectively scavenge free radical by improving the scavenging activity of DPPH and radicals as well as through elevated reducing and chelating efficiency in comparison with standard $\beta$-carotene. Existing evidence suggests that natural carotenoids can exist in the different isomeric forms ( $\beta$-carotene-trans or cis, especially cis form is highly active) and hence effectively quench free radicals and thus act as a better antioxidant than other synthetic antioxidant $[55,56]$.

\section{ACKNOWLEDGMENT}

This work was supported and funded by the project entitled "Biodiesel production from algae as a renewable energy source." Funding organization: Research Development and Innovation programme (RDI), Funding Program: EU-Egypt Innovation Fund, 2014-2017.

\section{CONFLICT OF INTERESTS}

Declared none.

\section{REFERENCES}

1. Bastard JP, Maachi M, Lagathu C, Kim MJ, Caron M, Vidal H, et al. Recent advances in the relationship between obesity, inflammation, and insulin resistance. Eur Cytokine Netw 2006;17:4-12.

2. Singh V, Gunjan KD, Katiyar D. Anti-inflammatory activity of alcoholic and aqueous heart wood extracts of Berberis aristata DC.
Asian J Pharm Clin Res 2014;7:210-2.

3. Wang X, Ge A, Cheng M, Guo F, Zhao M, Zhou X, et al. Increased hypothalamic inflammation associated with the susceptibility to obesity in rats exposed to high-hat diet. Exp Diabetes Res 2012;2012:1-8.

4. Than A, Zhang X, Leow MK, Poh CL, Chong SK, Chen P. Apelin attenuates oxidative stress in human adipocytes. J Biol Chem 2014;289:3763-74

5. Furukawa S, Fujita T, Shimabukuro M, Iwaki M, Yamada Y, Nakajima Y, et al. Increased oxidative stress in obesity and its impact on metabolic syndrome. J Clin Invest 2004;114:1752-61.

6. Whaley-Connell A, McCullough PA, Sowers JR. The role of oxidative stress in the metabolic syndrome. Rev Cardiovasc Med 2011:12:21-9.

7. Aviram M, Rosenblat M, Billecke S, Erogul J, Sorenson R, Bisgaier CL. Human serum paraoxonase (PON1) is inactivated by oxidized low density lipoprotein and preserved by antioxidants. Free Radic Biol Med 1999;26:892-904.

8. Kaikini A, Dhande S, Kadam V. Antihyperlipidemicactivity of methanolicextract of leaves of Bambusa bambos druce against poloxamer-407 induced hyperlipidemia in rats. Int J Pharm Pharm Sci 2015;7:393-8

9. Garg A, Singh R. Antiobesity activity of ethanolic extract of Cassia auriculatain high fat diet induced obese rats. Int J Pharm Pharm Sci 2015;7:237-43.

10. Williams KH, De Ribeiro AJ, Prakoso E, Veillard AS, Shackel NA, Brooks B, et al. Circulating dipeptidyl peptidase-4 activity correlates with measures of hepatocyte apoptosis and fibrosis in non-alcoholic fatty liver disease in Type 2 diabetes mellitus and obesity: A dual cohort cross-sectional study. J Diabetes 2015;7:809-19.

11. Yamaguchi H, Chen J, Bhalla K, Wang HG. Regulation of Bax activation and apoptotic response to microtubule-damaging agents by p53 transcription-dependent and-independent pathways. J Biol Chem 2004;279:39431-7

12. Zhu C, Xie P, Zhao F, Zhang L, An W, Zhan Y. Mechanism of the promotion of steatotic HepG2 cellapoptosis by cholesterol. Int J Clin Exp Pathol 2014;7:6807-13.

13. Talero E, García-Mauriño S, Ávila-Román J, Rodríguez-Luna A, Alcaide A, Motilva V. Bioactive compounds isolated from microalgae in chronic inflammation and cancer. Mar Drugs 2015;13:6152-209.

14. Pasquet V, Morisset P, Ihammouine S, Chepied A, Aumailley L, Berard JB, et al. Antiproliferative activity of violaxanthin isolated from bioguided fractionation of Dunaliella tertiolecta extracts. Mar Drugs 2011;9:819-31

15. Bhupathiraju SN, Wedick NM, Pan A, Manson JE, Rexrode KM, Willett WC, et al. Quantity and variety in fruit and vegetable intake and risk of coronary heart disease. Am J Clin Nutr 2013;98:1514-23.

16. Palozza P, Serini S, Maggiano N, Tringali G, Navarra $P$, Ranelletti FO, et al. Beta-carotene downregulates the steady-state and heregulin-alpha-induced COX-2 pathways in colon cancer cells. J Nutr 2005;135:129-36.

17. Stanier RY, Kunisawa R, Cohn-Bazire G. Purification and properties of unicellular blue green algae (order Chroococcales). Bacteriol Rev 1971;35:171-205.

18. Liang H, Ma A, Zhang P, Bi SL, Shi DY. Effect of ethanol extract of alga Laurencia supplementation on DNA oxidation and alkylation damage in mice. Asia Pac J Clin Nutr 2007;16 Suppl 1:164-8.

19. Adaramoye OA, Akintayo O, Achem J, Fafunso MA. Lipid-lowering effects of methanolic extracts of Vernoniaany gdalina leaves in rats fed on high cholesterol diet. Vasc Health Risk Manage 2008;4:235-41.

20. Shalaby HM, Tawfek NS, Hussein BK, El-Ghany MS. The assessment of some biochemical and immunological effects by amphetamine and orlistat on obesity in rats. Food Public Health 2014;4:185-92.

21. Ruperez FJ, Garcia-Martinez D, Baena B, Maeso N, Cifuentes A, Barbas C. Evolution of oxidative stress parameters and response to oral Vitamins $\mathrm{E}$ and $\mathrm{C}$ in streptozotocin-induced diabetic rats. J Pharm Pharmacol 2008;60:871-8.

22. Bafikol M, Bafikol G, Deniz K, Ozbakir O, Yücesoy M. New marker for lipid peroxidation: Serum paraoxonase activity in non-alcoholic steatohepatitis. Turk J Gastroenterol 2005;16:119-23.

23. Ruiz-Larrea MB, Leal AM, Liza M, Lacort M, de Groot H. Antioxidant effects of estradiol and 2-hydroxyestradiol on iron-induced lipid peroxidation of rat liver microsomes. Steroids 1994;59:383-8.

24. Prijanti AR, Marissa N, Paramita R, Humaira S, Nabila EN, Wijaya AE, et al. Analysis of oxidative stress markers malondialdehyde, glutathione, nitric oxide, and prorenin level in preeclampsia placental tissues. Asian J Pharm Clin Res 2018;11:158-61.

25. El-Baz FK, Aly HF, Ali GH. Neuromodulating effect of Dunaliella salina extract in the regression of Alzheimer's disease in rats. Int $\mathrm{J}$ 
Pharm Biol Sci 2016;7:921-31

26. Selek S, Aslan M, Nazligul Y. Serum PON1 activity and oxidative stress in non-alcoholic fatty liver disease. J Harran Univ Med Fac 2012;9:85-91.

27. Drury RA, Wallington EA. Carleton's Histology Technique. $4^{\text {th }}$ ed. New York, USA: Oxford University Press; 1967. p. 653-61.

28. Milanski M, Degasperi G, Coope A, Morari J, Denis R, Cintra DE, et al. Saturated fatty acids produce an inflammatory response predominantly through the activation of TLR4 signaling in hypothalamus: Implications for the pathogenesis of obesity. J Neurosci 2009;29:359-70.

29. Zhang X, Zhang G, Zhang H, Karin M, Bai H, Cai D. Hypothalamic IKK $\beta / \mathrm{NF}-\kappa \mathrm{B}$ and ER stress link overnutrition to energy imbalance and obesity. Cell 2008;135:61-73.

30. Abdel-Salam OM, Youness ER, Mohammed NA, Abu-Elhamed WA. Nuclear FACTOR-kappa B and other oxidative stress biomarkers in serum of autistic children. Open J Mol Integr Physiol 2015;5:18-27.

31. Cerpa-CruzS, González-Díaz V, Martínez-Bonilla G, Gutiérrez-Ureña S, Rodríguez-Cortés E, Garcia-Espinosa LA, et al. Non-alcoholic fatty steatohepatitis an inflammatory disorder beyond the liver. J Clin Cell Immunol 2013;4:1-8.

32. Baranova A, Younossi ZM. Adipokines in non-alcoholic fatty liver disease. In: Fantuzzi G, Mazzone T, editors. Adipose Tissue and Adipokines in Health and Disease, Nutrition and Health. Totowa, NJ: Humana Press Inc.; 2007.

33. Briscini L, Tonello C, Dioni L, Carruba MO, Nisoli E. BCL2 and Bax are involved in the sympathetic protection of brown adipocytes from obesity-linked apoptosis. FEBS Lett 1998;431:80-4.

34. Lavallard VJ, Gual P. Autophagy and non-alcoholic fatty liver disease. Bio Med Res Int 2014;2014:1-13.

35. Chen A, Mumick S, Zhang C, Lamb J, Dai H, Weingarth D, et al. Diet induction of monocyte chemoattractant protein-1 and its impact on obesity. Obes Res 2005;13:1311-20.

36. Sartipy P, Loskuroff DJ. Monocyte chemoattractant Protein 1 in obesity and insulin resistance. Proc Natl Acad Sci USA 2003;100:7265-70.

37. Kitade H, Chen G, Ni Y, Ota T. Nonalcoholic fatty liver disease and insulin resistance: New insights and potential new treatments. Nutrients 2017;9:E387.

38. Abulmeaty MM, Ahmed SA, Almajwal AM. Apelin is promising in management of diabetes complicating high fat diet induced obesity in rats. Prog Nutr 2013;15:245-54.

39. Lu Y, Zhu X, Liang GX, Cui RR, Liu Y, Wu SS, et al. Apelin-APJ induces ICAM-1, VCAM-1 and MCP-1 expression via NF-kB/JNK signal pathway in human umbilical vein endothelial cells. Amino Acids 2012;43:2125-36

40. Yasuzaki H, Yoshida S, Hashimoto T, Shibata W, Inamori M, Toya Y, et al. Involvement of the apelin receptor APJ in Fas-induced liver injury. Liver Int 2013;33:118-26.

41. Chiu HF, Liao JY, Lu YY, Han YC, Shen YC, Venkatakrishnan K, et al. Anti-proliferative, anti-inflammatory and pro-apoptotic effects of Dunaliella salina on human KB oral carcinoma cells. J Food Biochem 2017;41:e12349.
42. Bai SK, Lee SJ, Na HJ, Ha KS, Han JA, Lee H, et al. Beta-carotene inhibits inflammatory gene expression in lipopolysaccharide-stimulated macrophages by suppressing redox-based NF-kappa B activation. Exp Mol Mol Med 2005;37(4):323-34.

43. Jang SH, Lim JW, Kim H. Beta-carotene inhibits Helicobacter pyloriinduced expression of inducible nitric oxide synthase and cyclooxygenase-2 in human gastric epithelial AGS cells. J Physiol Pharmacol 2009;60:131-7.

44. Jayappriyan KR, Renganathan R, Venkatakrishnan V, Rengasamy R. In vitro anticancer activity of natural $\beta$-carotene from Dunaliella salina EU5891199 in PC-3 cells. Biomed Prev Nutr 2013;3:99-105.

45. Palozza P, Serini S, Maggiano N, Angelini M, Boninsegna A, Di Nicuolo $\mathrm{F}$, et al. Induction of cell cycle arrest and apoptosis in human colon adenocarcinoma cell lines by $\beta$-carotene through down-regulation of cyclin A and BCL2 family proteins. Carcinogenesis 2002;23:11-8.

46. Qiu X, Yuan Y, Vaishnav A, Tessel MA, Nonn L, van Breemen RB. Effects of lycopene on protein expression in human primary prostatic epithelial cells. Cancer Prev Res (Phila) 2013;6:419-27.

47. Ferré N, Camps J, Cabré M, Paul A, Joven J. Hepatic paraoxanase activity alterations and free radical production in rats with experimental cirrhosis. Metabolism 2001;50:997-1000.

48. Kumon Y, Nakauchi Y, Suehiro T, Shiinoki T, Tanimoto N, Nakamura T, et al. Pro inflammatory cytokines but not acute phase serum amyloid a or reactive protein, down-regulates paraoxonase 1 (PON1) expression by HepG2. Amyloid 2002;9:160-4.

49. Vincent HK, Powers SK, Dirks AJ, Scarpace PJ. Mechanism for obesity induced increase in myocardial lipid per-oxidation. Int J Obes Relat Metab Disord 200;25:378-88.

50. Amirkhizi F, Siassi F, Minaie S, Djalali M, Rahimi A, Chamari M. Is obesity associated with increased plasma lipid peroxidation and oxidative stress in women. ARYA Atheroscler J 2007;2:189-92.

51. Noeman SA, Hamooda HE, Baalash AA. Biochemical study of oxidative stress markers in the liver, kidney and heart of high fat diet induced obesity in rats. Diabetol Metab Syndr 2011;3:17.

52. García-González M, Moreno J, Manzano JC, Florencio FJ, Guerrero MG. Production of Dunaliella salina biomass rich in 9-cis$\beta$-carotene and lutein in a closed tubular photobioreactor. J Biotechnol 2005;115:81-90.

53. Yang DJ, Lin JT, Chen YC, Liu SC, Lu FJ, Chang TJ, et al. Suppressive effect of carotenoid extract of Dunaliella salina alga on production of LPS-stimulated pro-inflammatory mediators in RAW264.7 cells via NF- $\kappa B$ and JNK inactivation. J Funct Foods 2013;5:607-15.

54. Ben-Amotz A, Fishier R. Analysis of carotenoids with emphasis on 9-cis $\beta$-carotene in vegetables and fruits commonly consumed in Israel. Food Chem 1998;62:515-20.

55. Kao FJ, Chiu YS, Chiang WD. Effect of water cooking on antioxidant capacity of carotenoid-rich vegetables in Taiwan. J Food Drug Anal 2014;22:202-9.

56. Murthy KC, Vanitha A, Rajesha J, Swamy MM, Sowmya P, Ravishankar GA. In vivo antioxidant activity of carotenoids from Dunaliella salina-a green microalga. Life Sci 2005;76:1381-90. 